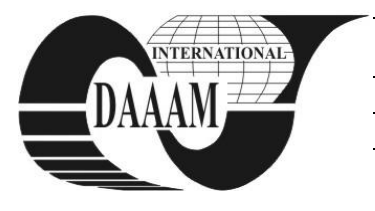

Annals of DAAAM for 2012 \& Proceedings of the 23rd International DAAAM Symposium, Volume 23, No.1, ISSN 2304-1382 ISBN 978-3-901509-91-9, CDROM version, Ed. B. Katalinic, Published by DAAAM International, Vienna, Austria, EU, 2012 Make Harmony between Technology and Nature, and Your Mind will Fly Free as a Bird Annals \& Proceedings of DAAAM International 2012

\title{
THE ROLE OF CULTURAL INTELLIGENCE (CQ) IN THE STRATEGY FORMULATION PROCESS - APPLICATION TO THE HOTEL INDUSTRY
}

\author{
LJUBICA, J[asenko] \& DULCIC, Z[elimir]
}

\begin{abstract}
Operating in international markets always remains a master challenge facing companies with global aspirations. In hospitality industry, characterized by intense cultural pluralism, new tools enabling top management to operate (more) successfully will be shown to have a crucial importance for the future. Although the concept of Cultural Intelligence has been discussed continually over the last decade, this paper will firstly refer to the layout of the $C Q$ construct in order to explain its application possibility in the hotel industry. This application, as viewed by authors, can be described as a filtering mechanism for the top management in the strategy formulation domain including three main phases: information processing, risk diminution and cultural interaction. Set in this manner, this theory represents a new role, application area and practical methodology for the concept of Cultural Intelligence, valuable to strategy makers in the international hospitality industry.

Keywords: cultural intelligence, hotes industry, strategy formulation
\end{abstract}

\section{INTRODUCTION}

There has been an exponential growth in the need for hospitality services worldwide. Firms, customers and employees have all become international and multicultural (Kandampully, 2002). Most deluxe hotels anywhere in the world expect their guests to be foreign. On this ground, the importance of effective cross-cultural management in the hospitality industry is being increasingly recognized as it enables the adequate promotion of hotel services, creating a positive impression on the customer and also enhancing the overall image of the property. The role of service providers, therefore, takes a leap forward when dealing with international customers. If service managers are unaware of the core multicultural expectations of customers, it will result in gap of performance of service (Moshin, 2006). Therefore, cultural differences need to be respected and accommodated for, while transacting in the people intensive sector like hospitality.

In the hospitality industry the true measure of company's success lies in organization's ability to continuously satisfy customers to gain a competitive edge by acknowledging and managing customers of different cultural backgrounds (Kandampully, 2001). Accordingly, when designing global strategy, from a hotel enterprise point of view, regional and cultural aspects must be taken into account. Culture holds an impact upon the perception and problem solving of global customers leading to a difference in the satisfaction level for the same service (Arora \& Rohmetra, 2010). In this context, Heo (2004) points out service providers, such as hotels, must be able to accommodate culturally based needs to tap into the increasingly lucrative market of international travelers. Thus, it is important to understand how it is indispensable for the hospitality organizations to embrace diversity to strengthen its business and give it a competitive advantage. On this ground, we argue that Cultural Intelligence (CQ), as a multidimensional socialmental construct, provides an opportunity to explore, understand and interact with diverse cultures more effectively with respect to the company goals and well being of the different culture(s) themselves. CQ thus transforms into a strategic tool enabling top hotel management to optimize the way they produce as well as implement global strategies which clearly enlightens the importance of CQs role in this domain. Therefore, the main objective of this paper is to theoretically explain the process through which this is achieved as described further on.

\section{LITERATURE REVIEW}

Business in the global context has implicitly increased interest in the cross cultural management research. Still, cultural diversities remain a challenge to be dealt by individuals and organizations. Literature on Cultural Intelligence is available in the period of the last decade as the concept is relatively new and that on the impact of culture on the respective industry from the year 1988 onwards.

Cultural Intelligence (CQ) is defined as a multidimensional construct that encompasses an individual's capability to function effectively in culturally diverse settings (Early \& Ang, 2003). This definition can be seen to be consistent with Schmidt's and Hunter' s (2000) definition of general Intelligence as "the ability to grasp and reason correctly with abstractions (concepts) and solve problems". Cultural Intelligence, therefore, applies to multiple cultural settings (Thomas, 2006).

As conceived by Van Dyne, Ang and Koh (2008) the factors that make up the discrete construct of cultural intelligence (Total Cultural Intelligence or TCQ) include: Meta-cognitive CQ, Cognitive CQ, Motivational CQ and Behavioral CQ. Meta-cognitive CQ refers to the conscious awareness which an individual has regarding cultural interactions. Cognitive CQ is seen to reflect the knowledge of a group's beliefs, values and norms. Motivational CQ reflects the capability to direct energy 
to learning about cultural differences. Finally, Behavioral CQ reflects the capability to choose appropriate verbal and physical actions when interacting eith people of different cultures.

Further on, Ng \& Early (2006) discussed conceptual distinctions between CQ, a culture - free construct and the traditional view of intelligence that is culture-bond; Triandis (2006) discussed theoretical relationships between CQ capabilities and forming accurate judgement. Brislin (2006) discussed CQ's role for "expecting the unexpected" during intercultural encounters.

Research on Cultural Intelligence have provided for conducting researches in the service sector. Therefore, the relevance for choosing the International Hospitality industry can be delineated on the fact that the industry is composed of individuals who come from diverse cultural backgrounds and that is relevant to acknowledge the differences that exist in their approach towards customer related outcomes in order to ensure success. Based on the fact that hospitality services are "high contact" services with a high degree of human involvement and face to face contact (Lovelock, Patterson \& Walker, 2001), numerous researches have attempted to apply Customer Satisfaction theories in the areas of tourism (Pizam \& Milman, 1993; Danaher \& Arweiler, 1996; Ryan \& Cliff, 1997, Hudson \& Shepard, 1998) in order to investigate Customer Satisfaction applicability to the hospitality and tourism industries. These researches pointed out that hospitality organizations, including hotels, must firstly understand who their customer is and, in this sense, identify their competitive advantages they can have over the other while dealing with customers from different cultural backgrounds.

As stated before, when designing global hospitality strategies different regional and cultural aspects must be taken into account. And indeed, studies conducted by Chadee \& Mattson (1995) and Scott and Shieff (1993) found significant cross-cultural differences in customer expectations and satisfaction. They found out that services and products important to Asians may not be of the same value or completely different from those sought by Europeans.

Strauss and Mang (1999) found out that problems for hospitality organizations appear because the performance of the domestic service provider (the hotel enterprise) does not meet the expectations of the foreign customer (inter-cultural provider performance gap).

Matilla (1999) investigated the influence of culture on consumer perceptions of service encounters. He found out that, in terms of first class hotels, cultural factors are likely to mediate the hotel customer's attitude toward the service component of their service experience.

Previous research has suggested that CQ has an impact on cross-cultural adaptation (Ward \& Fischer, 2008), task performance (Ang st. sl., 2007), on trust (Rockstuhl \& Ng, 2008), on group performance (Huber \& Lewis, 2010), expatriate performance (Lee \& Sukoco, 2010) and global leadership skills (Ng, Van Dyne \& Ang, 2009). While the stated areas have been thoroughly examined there has been significant gap in research investigating the role of $\mathrm{CQ}$ in the hospitality organizations strategy design process.

\section{PROPOSED MODEL}

As stated, significant research has not yet been conducted to investigate the relationship between Cultural Intelligence and strategic orientation of the hospitality organizations as well as the role of Cultural Intelligence in the strategy design process. On this basis, theoretical model is created to enlighten the role of CQ in the international hospitality sector with emphasis on its role in the strategy formulation domain. On this basis we argue that $C Q$ has significant role in this process consisting out of three main duties (Fig. 1):

- $\mathrm{CQ}$ as an information processing enhancement factor

- $\quad \mathrm{QQ}$ as risk diminution factor

$\mathrm{CQ}$ as a cross-cultural interaction moderator

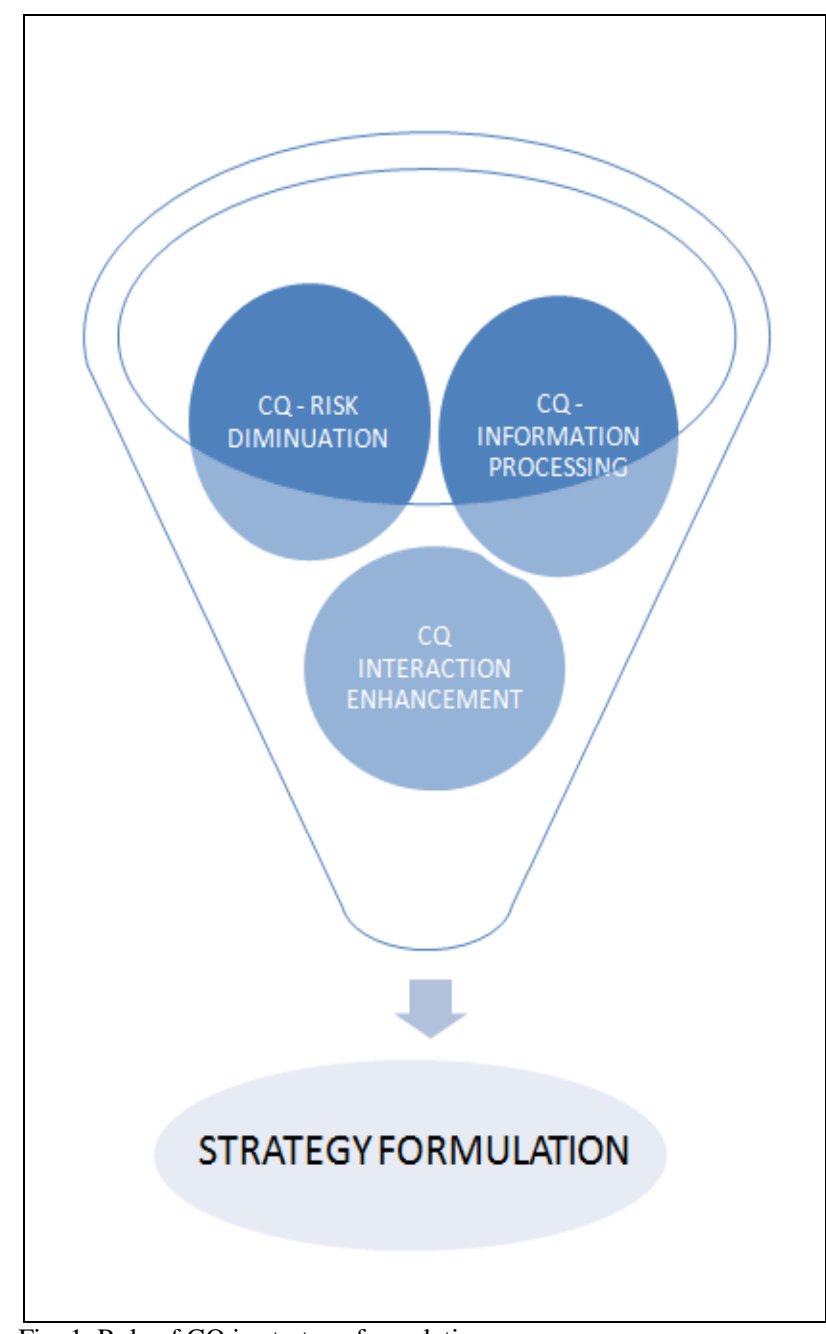

Fig. 1. Role of CQ in strategy formulation process

This model considers the important and diverse impacts of CQ in top executive perceptions, actions and performance and can provide a foundation from which to further extend effective strategy design dimension for top hotel management. 


\subsection{CQ as an information processing enhancement factor}

The first part of the proposed model builds up on the argument that $\mathrm{CQ}$ can act as a cognitive lens for executives and influence the way they process information about and from the environment (Mannor, 2008), which is a key task in the strategy formulation process. Specifically, information-processing factors such as environmental scanning (Sutcliffe, 1994) and the specific resources used to gather information for critical decisions (Daft, Sormunen \& Parks, 1988; McDonald \& Westphal, 2003) are both dimensions that may be influenced by the lens of CQ. On this ground, the CQ of major hotel executives is posited to influence three dimensions of executive information processing in three key aspects; (1) the information they look for, (2) the types of informational resources they rely on and (3) the overall quality of information that they are able to gather from the environment.

In support of the first parameter, study by Sutcliffe \& Huber, (1998) has suggested that the way the managers scan their environment firmly depends on their personal experiences and values. In this sense, managers who come from an engineering background tend to focus more on the technical dimensions of their environment while executives from sales and marketing background rely on the consumer - centered dimensions of the surroundings. Congruently, executives who are less comfortable and familiar with cultures different from their own (i.e. possess lower CQ) are less likely to engage in wide intercultural search or scanning behaviors that would require them to explore many unfamiliar information in external environment important, if not critical for the optimal strategy design. On the other hand, executives who are strong(er) in these areas (i.e. posses higher CQ) are likely to draw on their knowledge of different cultures when engaging in scanning, as people tend to search for information in locations that are familiar and comfortable to them (Stuart \& Podolny, 1996; Rosenkopf \& Nerkar, 2001). In conclusion, due to the fact that the executives with higher levels of CQ have specific knowledge and structures for understanding culturally diverse settings (based on the cognitive lens dimensions of CQ) they are more likely to search through a wider range of information-rich and culturally diverse locations for information. The result is a broader and more extensive, and therefore, more lucrative, search of the information in the company's external environment. Information referred to here are those of desires, needs, beliefs, attitudes, expectations and other core cultural characteristics of travelers in emissive markets. Identifying, collecting, analyzing and utilizing information will, without any doubt, enable top hotel management to formulate effective strategy for the organization in comparison to the situation in which they would not have them.

Second, the specific resources that executives utilize in their attempts to process information represent another role (2) of CQ, that of an information processing enhancer. These information resources are likely to differ depending on the CQ of managers (Mannor, 2008). More culturally intelligent managers will, therefore, have knowledge of informational resources that less culturally intelligent executives do not, and will be more willing to search out direct and embedded sources of culturespecific information than other managers. This knowledge makes it easier and more likely that executives with higher CQ would use informational resources generated from within a culture, rather than descriptions of cultural phenomena that originate from outside a culture. Knowledge of the informational resources can, therefore, be described as half the battle in finding good informational resources (Brucks, 1985). In strategic point of view, we argue that hotel managers with higher levels of CQ are more able to gain access to higher quality information relative to the strategic goals set for the hotel enterprise.

Third, we argue that top hotel managers with high levels of CQ are more able to gain access to higher quality information relative to the strategic goals of their organization. To support this, we emphasize that executives with higher levels of CQ have better knowledge of cultural differences which allows them to better sort through and identify high-quality information from the environment. Culturally intelligent hotel managers are, therefore, more likely to persist in information search efforts to find high-quality information, due to their high levels of motivation for engaging with diverse cultures.

\subsection{CQ as risk diminution factor}

It is an assuredly fact that strategy formulation is an extremely risky venture. It draws, among other, a great amount of work as well as funds with an uncertain outcome especially with strong competition inside and outside the tourist destination. These risks suggest hotel managers should investigate thoroughly the psychological, social as well as cultural characteristics of the emissive markets in order to design an appropriate strategy and finally achieve strategic goals.

Although strategic goals in the form of economic results are subject to various business parameters they also, almost always, in long-term sense, depend on the guest satisfaction. Congruently, guest satisfaction is achieved in recognizing their needs, expectations and desires and through products designed to comply with those settings. This suggests that forming a strategy designed to penetrate culturally unfamiliar markets is risky for any organization, especially the hospitality one. Such risks are mitigated to a large degree by the CQ of the top management in charge for the design of the strategy itself. Specifically, these risks are reduced because more culturally intelligent managers have greater knowledge of cultural differences and cultural attributes of the emissive markets and are therefore more adept at engaging in behavioral flexibility and, thus, have the intrinsic motivation to fully engage with culturally distant markets (Schaffer \& Harrison, 1998).

These factors come together to make the strategy itself higher quality, and thus more likely based on cultural characteristics of the potential guests rather than on calculated risk. Congruently, it can be underlined that hotel managers with low CQ levels are less able to communicate effectively and understand the core cultural 
expectations of travelers from the emissive markets. Further on, such managers have less common ground to build the optimal strategy upon and the cultural distance between the strategy and strategic orientation of the hotel enterprise and the travelers themselves may be magnified. Relying on the cultural characteristics of the emissive markets means building a long-term relationship with the guests by acknowledging, familiarizing with and satisfying their needs instead concentrating on the relationship that is built on short term financial opportunism which is rapidly recognized and rejected by the guests themselves.

\subsection{CQ as a cross-cultural interaction moderator}

Forming a strategy for the hotel enterprise in the modern globalized world reflects, actually, the term "thinking globally". "Thinking globally" means extending concepts and models from "one to one" relationship to holding multiple realities and relationships in mind simultaneously and then skillfully on this more complex reality (Lane, Di Stefano \& Maznevski, 1997). Thinking globally refers to the ability to balance different complex forces in pursuit of a unique strategy that blends them (Bartlett \& Ghosal, 1989). In this sense, hotel managers are indeed responsible for worldwide search, identification, acknowledgement and management of cultural characteristics of people from many different countries that together form emissive markets of special interest to the hotel enterprise. This is where the importance of Cultural Intelligence assumes its moderating role. We argue that the moderating role of CQ actually enables managers with high levels of CQ to be more successful in recognizing cultural characteristics of travelers from different cultures and, therefore, enables them to create appropriate strategy in order to attract them and make them, in fact, a loyal hotel guests. This is even more important in large hotel chains working on world scale due to the possibility that such companies can offer a multi-destination and, thus, multicultural experience.

More thorough theoretical investigation suggests that cognitive dimension of CQ represents a hotel manager's ability to assess the similarities and differences in cultural surroundings in ways that allows him or her to take appropriate strategic attitude in company terms. As cognitive CQ actually represents knowledge, it is more than evident that knowledge is highly important because one needs to understand why somebody "acts the way he or she does". In other words, one needs to know "what is desirable and what is not" in specific culture in order to create a product that will intrigue members of that culture and make them want to buy it. Such knowledge represents the knowledge of specific culture-bound behaviors, norms, religious and other beliefs, marriage systems, arts and crafts (Ang \& Van Dyne, 2008).

The behavioral dimension of CQ reflects individual's flexibility in exhibiting appropriate behavior when interacting with people who differ in cultural background (Early \& Ang, 2003). This is crucial in hospitality due to the fact it is based on human interaction and behavior as a critical quality criterion. It also enlightens openness toward culture as a basis for successful strategy formulation as well as implementation when penetrating culturally diverse emissive markets. In comparison, hotel managers with low CQ levels will take more personal attitude than a cultural approach, they will focus on cultural stereotypes rather than on values and they will rely on locally available information rather than gaining more thorough cultural knowledge themselves (Janssens \& Cappellen, 2008) which is critical error and, in most cases, predicts poor strategy as well as poor service and overall performance for hotel enterprises.

Meta-cognitive CQ refers to consciousness about cultural differences. This is important because it enables hotel managers to detach themselves from their own cultural framework and, in that sense, enables them not to take their own culture as the norm or basis of what counts on a worldwide scale. Strategy formed in this manner is truly traveler oriented and represents the most efficient way to success, especially in the hospitality industry that is strictly guest oriented.

Finally, motivational dimension of CQ reflects the ability and motivation to use cultural knowledge and produce a culturally appropriate response (Early \& Ang, 2003). Among other, it refers to an individual's drive to learn about different cultures and extract valuable information necessary. In this case, that means crosscultural modification of the strategic representation of the hotel enterprise to potential partners and the travelers themselves.

\section{DISCUSSION}

From the hospitality industry point of view, globalization often means increased reliance on crosscultural adaptive skills of managers. On this basis it becomes critical to gain a better and more clear and precise understanding of the factors that enable hospitality managers to perform effectively in culturally diverse contexts they operate in. One of those contexts with crucial values for the hotel enterprise is, without any doubt, a strategy formulation domain. Congruently, the greatest challenges facing top management of modern hotel enterprises will be acknowledging, managing and complying to customer needs across cultures as a basis for successful strategy production.

However, "little theory or research has been set forth on how values are converted into action" (Finklestein \& Hambrick, 1996, p. 51). On this basis we introduced the concept of Cultural Intelligence as a filtering mechanism that enables hotel management to design a more effective strategy based on (more) clear understanding and managing of the cultural differences. Due to the fact that tourism and hospitality are people centered industries, strategy design is in firm correlation with the social, psychological and cultural settings of the emissive markets, formulating an effective, guest oriented strategy shapes the path to long-term success of the hotels. Following that fact we proposed a model through which CQ acts like an environmental information scan, risk diminution and cultural interaction optimizer through three phases of the process. 
Our main argument proposed in this paper was the enrollment of Cultural Intelligence, as a managerial capability to function effectively in the surroundings characterized by multiculturalism, as an enhancement tool in the strategy design process for the hotel enterprises. We explained how all categories of CQ, being a multidimensional construct, can help to create a more effective strategy than it would be done by managers with no or lower levels of CQ. The first category examined how meta-cognitive and cognitive dimension of CQ can create a cognitive lens (Mannor, 2008) for managerial information processing. Specifically, CQ was shown to enable managers to identify specific types of information, types of informational resources and information of higher quality and thus form a more firm basis for the creation of a customer oriented strategy. In this tradition, degree to which a manager's social construction of reality (Weick, 1979) can restrict his or hers vision, search for explanations and information processing will result in less biased decision than it would culturally less intelligent managers.

Next argument presented was that CQ actually works as a risk diminution factor in the strategy design process due to the fact that culturally intelligent managers are able to recognize and manage cultural diversity of the emissive markets faster, more thorough and more effective and, on that grounds, formulate a strategy based on the actual, conscious and even subconscious needs and desires of the travelers, which, again, in the hospitality industry represents a valuable competitive advantage.

Finally, CQ was proposed to take on a cross-cultural interaction moderator role due to the fact that all of his constructive dimensions represent, in fact, a mechanism that enables managers, as well as other parties contributing to the hotel enterprise strategy formulation process, to: assess the similarities and differences in cultural surroundings (cognitive CQ), to be open toward culture as a basis for successful strategy formulation (behavioral CQ), to be conscious about cultural differences (meta-cognitive CQ) and to be able to use cultural knowledge and produce a culturally appropriate response in the form of a strategy itself (motivational CQ).

Cultural intelligence as a cross-cultural contact tool has a vast application area. In hospitality industry, where that cultural contact assumes crucial role in terms of service quality as well as performance outcome predictor, it is extremely important to develop and foster capabilities that enables both managers and employees to be effective in multicultural surroundings which tourism is based on. Cultural Intelligence, as proposed within this paper, has information processing enhancement, risk decrease and cross-cultural interaction moderating role, all focused to optimize a hotel enterprise strategy design process. Congruently, from the economic point of view, it also reflects the performance domain in terms of increasing profits through fostering loyal and satisfied customers.

\section{LIMITATIONS AND FUTURE RESEARCH RECCOMENDATIONS}

Main limitations regarding the theory presented in this paper are based on a fact that Cultural Intelligence surfaced in the literature nearly decade ago following the inter-cultural management literature up to date. Congruently, there is still a vast area regarding the construct itself as well as its application directions that remains inadequately investigated, especially from the empirical point of view. Also, even though the number of CQ researchers increases linearly with time, the tourism and hospitality domain, for some reason, remain forsaken in terms of further enlightenment of the Cultural Intelligence role in that area.

When we take into account the fact that tourism and hospitality are in fact global and therefore multicultural phenomena, the need and importance of further scientific investigation of CQ and its role in this area is more than evident. Inclusively, our theory was created with respect to the previous studies and up to date literature combined with our professional beliefs and attitudes regarding the issue at hand. However, the fact that the linkage between CQ and hospitality management remain under-researched and therefore without strong empirical evidence still represents the main flaw and limitation to any study concerning CQ and hospitality as well as this one. It is extremely necessary to maximize the amount of theoretical and empirical body in order to remedy the situation as it is and to provide the studies with more value and relevance.

Although CQ is relatively new construct that surfaced in the literature decade ago, there has been extensive research that provided the constitution of its layout and its implications in the business economics area in terms of achievement, performance, cross-cultural adaptation, human resources management and other significant fields. However, little research has been done to explore it's role and implementation in the service industry such as tourism and hospitality. Based on the fact that tourism and hospitality industry is people's needs, desires and expectations industry, the importance of acknowledging, understanding, training, managing and, finally, further exploring the potentials of Cultural Intelligence throughout all levels of the hospitality companies is, as stated before, clear. Such research should focus on the employee - customer interaction domain due to the fact that such relationship represents the core of the service quality perception from both guest and company point of view.

Further on, additional research is clearly necessary in order to investigate the relationship and effects of the managerial as well as employee Cultural Intelligence development degree to job satisfaction domain due to the fact it also represents a serious element influencing the performance and guest satisfaction dimension.

Also, the human potentials management and its relation with Cultural Intelligence is another area vital to the hospitality enterprises that should be thoroughly examined in order to establish training regimes for the managers as well as other employees.

\section{REFERENCES}

[1] Ang, S., Van Dyne, L., 2008, Conceptualization of Cultural intelligence: Definition, Distinctiveness and nomological 
network, in Ang and Van Dyne (Eds) Handbook of cultural intelligence: Theory measurement and applications, London: M.E. Sharpe, pp. 3-15

[2] Ang,S., Van Dyne, L., Koh,K., 2006, Personality correlates of the four factor model of cultural intelligence, Group and organization management, 31, pp. 100-123

[3] Arora, P., Rohmetra, N. (2010 Cultural Intelligence: Leveraging Differences to Bridge the Gap in the International Hospitality Industry, International Review of Business Research Papers, Vol. 6 No. 5, November 2010, pp. 216-234

[4] Bartlett, C., Ghosal, S., (1989), Managing across borders: The transnational solutions, Boston, MA: The Hrvard Bussines school press

[5] Brislin, R., Worthley, R., and McNab, B. (2006.) Cultural Intelligence: Understanding Behaviors that Serve People ${ }^{\text {ee }}$ Goals. Group and Organization Management, 31: 78, pp. 40- 45. DOI: 10.1177 / 1059601 - 105275266

[6] Brucks, M., (1995), The effects of product class knowledge on information search behaviour, Journal of consumer research, 12, $1-16$.

[7] Chadee, D. , Mattsson, J. (1995), Customer Satisfaction in Tourist Service Encounters, .Journal of Travel and Tourism Marketing; Vol 4,

[8] Daft, R.L., Sormunen, J., Parks, D., (1988), Chief executive scanning, enviromental characteristics and company performance - an empirical study, Strategic management Journal, 9, 123-139.

[9] Danaher, P.J., Arweiler, N. (1996.) Customer Satisfaction in the tourist industry: a case study of visitors to New Zealand, Journal of Travel Research, vol 35 no.1, pp.89-93.

[10] Early, P.; Ang, S. (2003). Cultural intelligence: Individual Interactions across cultures, Palo Alto: Stanford University Press, ISSN: 0-8047-4300-2, California, USA

[11] Heo, J., , (2004). Customer focused adaptation in New York city hotels: exploring The perceptions of Japanese and Korean travelers, International Journal of Hospitality Management, Vol. 23, Iss. 1, March 2004, pp. 39-53.

[12] Huber, G., Lewis, K., (2010), Cross-cultural understanding: Implications for group cognition and performance, Academy of Management review, 35 (1), pp. 6-26

[13] Hudson, S. , Shepard, G.W.H. (1998.) Measuring service quality at tourist destinations: an application of importance-performance analysis to an alpine ski resort, Journal of Travel and Tourism Marketing, vol. 7 (3), pp.61-77.

[14] Janssens, M., Cappellen, T., (2008) Contextualizzing Cultural Intelligence: The case of global managers, in Ang and Van Dyne (Eds) Handbook of cultural intelligence: Theory measurement and applications, London: M.E. Sharpe, pp. 356- 371

[15] Jassawalla, A., 2004, Cross-cultural conflict and expatriate manager adjusment, Management decision, 42(7), pp. 837-849

[16] Kandampully, J.A.; (2002). Services Management: The new paradigm in hospitality, ISSN: 1694-0938, Pearson Aducation Australia, Franchs Forest, New South Wales, Australia

[17] Kim, K., Kirkman, B.L., Chen, G.,, 2008, Cultural Intelligence and international assignement effectiveness: A conceptual model and preliminary findings, in Ang and Van Dyne (Eds) Handbook of cultural intelligence: Theory measurement and applications, London: M.E. Sharpe, pp. 71-90

[18] Lane, H.W., Di Stefano, J.J., Mazniewski, M.L., (1997), International Management Behaviour (3rd Ed), Cambridge, MA: Blackwell

[19] Lee, L., Sukoco, B., (2010), The effects of Cultural Intelligence on expatriate performance: Ther moderating effects of International experience, Journal of Human resources management, 21(7), pp. 936-981

[20] Lovelock, C.H., Patterson, P.G., Walker, R.H. (2001.) Services Marketing: An Asia Pacific Perspective, 2nd ed., Australia: Pearson Education, ISBN: 9780733986789, Australia

[21] Mannor, M.J., 2008, Top execitives and global leadership: At the intersection of cultural intelligence and strategic leadeship theory, in Ang and Van Dyne (Eds) Handbook of cultural intelligence: Theory measurement and applications, London: M.E. Sharpe, pp. 91-106

[22] Mattila, A.S. (1999), The role of culture and purchase motivation in service encounter evaluations, Journal of Services Marketing, Vol 13 (4/5) pp. 376-389.
[23] McDonald, M.L., Westphal, J.D., (2003), Getting by with the advice from their friends: CEO advice networks and firms strategic responses to poor performance, Administrative Science Quartely, 48, pp. 1-32

[24] Moshin, A.; (2006). Cross-cultural sensitivities in hospitality: a matter of conflict or understanding, Proceedings of International Conference on excellence in the Home: Balanced Diet - balanced life, Royal garden Hotel, Kensington

[25] O Neill, M., Palmer, A., Survey timing and consumer perceptions of service quality: an overview of empirical evidence, Managing Service Quality, Vol. 11 Iss: 3,1991, pp.182 - 190

[26] Pizam, A., Milman, A. (1993.) Predicting satisfaction among first time visitors to a destination by using the expectancy disconfirmation theory, International Journal of Hospitality Management, Vol. 12 No. 2, May 1993, pp. 197-209

[27] Rockstuhl, T., Ng, K., (2008), The effects of Cultural Intelligence on interpersonal trust in multicultural teams, in Ang and Van Dyne (Eds) Handbook of cultural intelligence: Theory measurement and applications, ISBN: 978-0-7656-2262-4 London: M.E. Sharpe, pp. 206-220

[28] Rosenkopf, L., Nerkar, A., (2001), Beyond local search: boundary- spanning, exploration and impact in the optical disk industry, Strategic management Journal, 22, pp., 287 - 306

[29] Ryan, C., Cliff, A. (1997.) Do travel agencies measure up to customer expectations? An empirical investigation of travel agencies - service quality as measured by SERVQUAL, Journal of Travel and Tourism Marketing, Vol. 6 No. 2, pp. 1-31

[30] Schaffer, M.A., Harrison, D.A., 1998, Expatriate's psychological withdrawal from international assignements: Work, Nonwork and family influences, Personnel Psychology, 51, pp. 87-118

[31] Schaffer,M., Miller,G., Cultural intelligence: A key success factor for expatriates, in Ang and Van Dyne (Eds) Handbook of cultural intelligence: Theory measurement and applications, London: M.E. Sharpe, pp. 107-125

[32] Schmidt, F.L., Hunter, J.E., 2000, Select on intelligence, in E.A. Locke (Ed), The Blackwell handbook of organizational principles, Oxford: Blackwell, pp. 3-14

[33] Scott, D. , Shieff, D. (1993), Service quality components and group criteria in local government, International Journal of Service Industry Management, Vol. 4, No. 2, pp.18-25

[34] Stauss, B., Mang, P. (1999), Cultural shocks in inter-cultural service encounters?, Journal of Service Marketing ,vol $13(4 / 5)$ pp. 329-346

[35] Stuart, T.E., Podolny, J.M., (1996), Local search and the ovolution of the technological capabilities, Strategic Management Journal, 17, pp. 21-38

[36] Sutcliffe, K.M., (1994), What executives notice - accurate perceptions in top management teams, Academy of Management Journal, 17 , pp. $21-38$

[37] Sutcliffe, K.M., Huber, G.P. (1998), Firm and Industry as determinants of executive perceptions of the enviroment, Strategic management Journal, 19, pp. 793-807

[38] Thomas,D., (2006) Domain development of Cultural Intelligence: The importance of mindfullness, Group and Organization Management 31; 78, pp.78-99, DOI: 10.1177 / 1059601 105275266

[39] Triandis, H., (2008)Cultural Intelligence.; in Ang and Van Dyne (Eds) Handbook of cultural intelligence: Theory measurement and applications, ISBN: 978-0-7656-2262-4 London: M.E. Sharpe, pp. xi - xiii

[40] Van Dyne, L., Koh, K., Ang, S., Van Dyne, L., 2008, Conceptualization of Cultural intelligence: Definition, Distinctiveness and nomological network, in Ang and Van Dyne (Eds) Handbook of cultural intelligence: Theory measurement and applications, ISBN: 978-0-7656-2262-4 London: M.E. Sharpe, pp. 3-15

[41] Ward, C., Fischer, R., (2008) Personality, Cultural intelligence and cross-c ultural adaptation, in: Ang and Van Dyne (Eds) Handbook of cultural intelligence: Theory measurement and applications, ISBN: 978-0-7656-2262-4 London: M.E. Sharpe, pp. $159-173$

[42] Weick, K., (1979), The social psychology of organizing ( $2^{\text {nd }}$ ed.), Reading, MA: Addison-Wesley Wiersema, M.F., \& Bantel, K.A. (1992), Top Management team demography and corporate strategic change, Academy of management Journal, 35, pp. 91 121 